\title{
Additive and synergistic interactions of entomopathogenic fungi with Bacillus thuringiensis for the control of the European grapevine moth Lobesia botrana (Denis and Schiffermüller) (Lepidoptera: Tortricidae)
}

\author{
Evangelos Beris ${ }^{*}$ and Elias Korkas
}

\begin{abstract}
Background: The European grapevine moth, Lobesia botrana (Denis and Schiffermüller) (Lepidoptera:Tortricidae) is currently the most damaging pest in many viticultural regions across the Mediterranean basin and elsewhere. Its feeding activity also enhances the development of secondary infections by Botrytis cinerea - and other fungi - to wine grapes. The gram-positive bacterium Bacillus thuringiensis (Bt) has been reported to partially control larval populations of $L$. botrana, while it requires to be digested by the insect to cause infection. Entomopathogenic fungi (EPF) are possibly capable of acting synergistically with $B t$ to increase its efficacy against insect pests.

Results: The hypothesis of synergy or antagonism between Bt and EPF for the control of L. botrana was tested in two bioassays: A) Insects fed on Bt diet and subsequently some groups were sprayed by conidia of Beauveria bassiana or Paecilomyces fumosoroseus, and B) Grapes were sprayed by Bt, or B. bassiana, or combination of the two, and then untreated insects were placed to feed on the grapes. In both bioassays, combination treatments performed better than single treatments, indicating additive action or synergy. The Bt and B. bassiana combination treatment (Bt diet for $30 \mathrm{~h}$ and then sprayed with conidia of B. bassiana) resulted in $91 \%$ larval mortality while the single Bt and B. bassiana treatments caused $28 \%$ and $34 \%$ mortality respectively. Such results indicated synergism. Combination treatment on grapes also caused significantly higher mortality on L. botrana larvae, compared to single treatments. The median lethal time $\left(L T_{50}\right)$ was estimated as 8.43 days for the single $B t$ treatment, 7.87 days for the single B. bassiana treatment and 6.3 days for the combination $B t+B$. bassiana treatment.
\end{abstract}

Conclusions: Absence of antagonism as well as additive action or synergy were indicated by the results. Larval populations of the pest can be effectively controlled by using microbial biocontrol agents. Further research is needed to investigate the biotic and abiotic factors that affect interactions between insect hosts and entomopathogenic organisms. However, the entomopathogens used in the present study showed remarkable action and may be included parallelly in control strategies against vineyard pests.

Keywords: Lobesia botrana, Entomopathogenic fungi, Bacillus thuringiensis, Biological control, Vitis vinifera

*Correspondence: eberis@uniwa.gr

Department of Wine, Vine and Beverage Sciences, School of Food Sciences, University of West Attica, 12210 Aigaleo, Athens, Greece

\section{Background}

The European grapevine moth, Lobesia botrana (Denis and Schiffermüller) (Lepidoptera: Tortricidae) is the most damaging vineyard pest in South and Central Europe, 
while recently it has been reported to cause significant damages in important viticulture regions of Chile, Argentina and California (López-Plantey et al. 2019). It mainly damages grape berries and flowers (Moreau et al. 2010), while larval stage affects the level of damage (Delbac and Thiery 2015). The direct losses that L. botrana are often followed by secondary infections by Botrytis cinerea and several more fungi (Delbac et al. 2010). Direct infestations by $L$. botrana and damages caused by its subsequent fungal infections, have been reported to substantially affect the quality and quantity of the grapes, as well as the quality and chemical properties of the wines produced from those grapes (Ioriatti et al. 2011).

Chemical control has significant environmental, economic and public health impact in addition to the resistance that $L$. botrana develops to specific insecticidal chemical compounds (Durmuşoğlu et al. 2015). Common control strategies against the pest include the mating disruption technique (Ioriatti et al. 2011) and the use of egg parasitoids (Vogelweith et al. 2014). Alternative control approaches such as the exposure of the insect to Gamma irradiation (Mansour and Al-Attar 2014) and the use of nanotechnology (Benelli et al. 2020) have been recently tested.

Regarding microbial bio-control agents, Bacillus thuringiensis $(B t)$ has been proven to control larval populations of L. botrana (Ruiz de Escudero et al. 2007). Many $B t$ strains produce crystal proteins, called $\delta$-endotoxins, which have insecticidal action (Schünemann et al. 2014). The Cry toxin can be extracted and used as a bio-insecticide. Such insecticides have already been used in viticulture for controlling the European grapevine moth and other vineyard pests. Toxicity caused by $B t$ is considered as insect specific. This selective action of most $B t$ formulations, results in effective control of the populations of L. botrana without affecting the populations of its parasitoids and predatory insects and mites (Tzanakakis and Katsoyiannos 2003). However, the efficacy of $B t$ on pests, depends on multiple biotic and abiotic factors such as environments conditions (Moustafa et al. 2018). The physiology of $L$. botrana also depends substantially on environmental factors (Gutierrez et al. 2018; Reineke and Selim 2019). Furthermore, $B t$ needs to be digested by the insect to cause infection (Guo et al. 2019).

Entomopathogenic fungi (EPF) have been reported to present additional efficacy against insect pests when applied in combination with $B t$-based products. Although there is no information on the use of such combination treatments on L. botrana, results showing additive effects or synergistic interactions between EPF and $B t$ on the control of various pests, have been previously published. Interactions between B. bassiana and Cry1Ac (a toxic crystal protein produced by $B t$ ) were observed by
Ma et al. (2008) on laboratory bioassays for the control of Ostrinia furnacalis. Moreover, combined effects of $B$. bassiana and bio-insecticides based on $B t$ were investigated in field populations of Colorado potato beetle larvae (Wraight and Ramos 2005). Synergistic interactions of B. bassiana and $B t$ on control of the Colorado Potato Beetle were also reported by Costa et al. (2001), after applying sublethal stress with the CryIIIA $\delta$-endotoxin of $B t$ and subsequent exposure to B. bassiana.

In the present study, an attempt was made to investigate whether $B t$ can act synergistically with EPF for effective control of L. botrana.

\section{Methods}

\section{Insects}

Second and $3^{\text {rd }}$ larval instars of L. botrana were used in the following bioassays. Insects were reared, under controlled conditions, on a semisynthetic diet (Standard $L$. botrana diet) consisting of the following ingredients: distilled water $1.4 \mathrm{l}$, corn flour $225 \mathrm{~g}$, wheat germs $58 \mathrm{~g}$, agar $32 \mathrm{~g}$, brewing yeast $22 \mathrm{~g}$, sorbic acid $8 \mathrm{~g}$, Nipagin $4 \mathrm{~g}$, Benzoic acid $4 \mathrm{~g}$.

Larvae were initially collected, along with infested grapes, from a vineyard ( $V$. vinifera $\mathrm{cv}$. Savatiano) in the area of Spata (Attica - Greece). Then, infested grapes were placed in cages until first adult insects emerged. Adult female and male insects were placed on plastic cups, covered with filter paper on the top, and the females laid their eggs on the walls of the cups. Then, the cups were half-filled with artificial diet which was previously cut into cubes of about $1 \mathrm{~cm}$ length. When the eggs hatched, young larvae fed on diet until they pupated. After the emergence, all adult males and females were placed into plastic cups using a glass tube. The insects were left to lay their eggs for 3-4 days and then removed and killed. Adult insects fed on a solution of 5\% honey dissolved into distilled water, which was provided to the insects via a cotton disc placed on the bottom of the cups. The colony of L. botrana was maintained at a temperature of $24 \pm 1^{\circ} \mathrm{C}$ and $60 \pm 10 \%$ relative humidity. The photoperiod was 16:8 h (light: dark) and the luminosity $500 \mathrm{~lx}$ photophase. Insects used in both bioassays remained under starvation for $24 \mathrm{~h}$ before the initiation of the experiments.

\section{Bacillus thuringiensis}

Bacillus thuringiensis var. kurstaki (Dipel ES, 17,600 International Units (IU)/mg, Abbott, North Chicago, Illinois) was used at both following bioassays. Dipel ES contains Cry1Aa, Cry1Ab, Cry1Ac, Cry2A, and Cry2B endotoxins of $B t$ along with supplementary components which improve its performance as a microbial insecticide. For the In vitro test, $4 \mathrm{ml}$ of Dipel ES were 
dissolved in $1.4 \mathrm{l}$ of distilled water, which replaced the total amount of water in an individual block of semisynthetic diet $(1650 \mathrm{~g})$. This process resulted in a concentration of $\sim 42,700$ IU per $g$ of diet. For the latter bioassay, a concentration of $70,400 \mathrm{IU} / \mathrm{ml}$ was made by adding $2 \mathrm{ml}$ of Dipel ES into $500 \mathrm{ml}$ of sterile distilled water.

\section{Fungal preparations}

The EPF isolates B. bassiana IMI-391044 and P. fumosoroseus EBAC-01, as well as a commercial bio-insecticide based on B. bassiana strain GHA (BotaniGard ${ }^{\circledR}$ ES), were used at the following bioassays. The two non-commercialised fungi were initially isolated using the "Galleria Bait Method" (Zimmermann 1986). Upon initiation of the experiments, these isolates were sub-cultured and grown on $9 \mathrm{~cm} \varnothing$ Petri dishes with half-strength Sabouraud Dextrose Agar (SDA), at $25^{\circ} \mathrm{C}$ for 20 days. Spore suspensions of $1 \times 10^{8}$ conidia/ml were made for each isolate, by scraping conidia from the surface of the plates using a microscope slide. Then, a sterile liquid solution of distilled water with $0.1 \%$ Tween 80 was poured into the plates to remove, disperse and integrate the conidia. The containing conidia liquid suspension was stirred using a magnetic stirrer and filtered twice using a sterile nylon membrane. The dose of $1 \times 10^{8} \mathrm{conidia} / \mathrm{ml}$ was selected for all fungal treatments due to the highest efficacy levels that presented in previous bioassays. This concentration has been considered as optimum, especially for single concentration experiments (Galindo-Velasco et al. 2015). In the case of the commercial bio-pesticide (BotaniGard ${ }^{\circledR}$ ES), a spore suspension was adjusted to $1 \times 10^{8}$ conidia/ $\mathrm{ml}$ by dissolving $6.15 \mathrm{ml}$ of product into $500 \mathrm{ml}$ of sterile distilled water. All spore concentrations were measured, under microscope $(400 \times)$ ), using a standard (improved Neubauer) haemocytometer. When needed, extra distilled water was added to adjust the dilution until reaching the $1 \times 10^{8}$ conidia/ml concentration.

Spore viability was calculated by counting the percentage of germinated conidia, which were spread on half-strength SDA plates, under a microscope $(400 \times)$. B. bassiana IMI-391044 and P. fumosoroseus EBAC-01 presented conidial viability of 99 and $98.3 \%$, respectively while B. bassiana GHA (BotaniGard ${ }^{\circledR}$ ES) showed $96.7 \%$ spore viability. A concentration of $1 \times 10^{5}$ conidia/ml was made for each isolate, using the method described above; $100 \mu \mathrm{l}$ of the suspension was added on each plate using a micropipette and then spread using a microscope slide. After sealing, the plates were incubated at $25^{\circ} \mathrm{C}$ for $18 \mathrm{~h}$. Three sets of 100 conidia were measured for each isolate. All conidia with visible germ tubes of any length were counted as viable.

\section{Mortality of $L$. botrana larvae after exposure to $B t$ diet and subsequent fungal treatment}

The $2^{\text {nd }}$ instar L. botrana larvae were used in the present bioassay. For treatments involving $B t$ consumption, insects were exposed and fed on a diet, which contained $B t$ var. kurstaki (Dipel ES). Control larvae, as well as insects that were prepared for the single fungal treatments, were fed on standard L. botrana diet (described above). $B t$ diet was made exactly as the standard, except the addition of $4 \mathrm{ml}$ of the product (Dipel ES) in 1.41 of distilled water, which produces approximately $1650 \mathrm{~g}$ of diet $(42,700 \mathrm{IU} / \mathrm{g})$. Insects were fed on either diet in groups of 10 (5 groups for each treatment), inside sterile Petri dishes for $30 \mathrm{~h}$.

Subsequently, fungal treatments were applied by spraying the insects, using Mist trigger micro-sprayers "Hozelock 4120 Spray 0.5 l", inside sterile Petri dishes with filter paper covering the bottom of the plates. Ten larvae were placed into each dish. Insects were sprayed until the entire area of the paper was wet but not saturated. Single and combination $B$. bassiana and $P$. fumosoroseus treatments were sprayed with the respective suspensions $\left(1 \times 10^{8}\right.$ conidia/ml of sterile distilled water with $0.1 \%$ Tween 80 ). Control and single $B t$ insects were sprayed with a solution of sterile distilled water with $0.1 \%$ Tween 80 .

Therefore, six (6) groups of differently treated insects were evaluated:

1. Control: Larvae fed on standard L. botrana diet for $30 \mathrm{~h}$ and then, sprayed with sterile distilled water.

2. Bt: Larvae fed on $B t$ diet for $30 \mathrm{~h}$ and then, sprayed with sterile distilled water.

3. B. bassiana: Larvae fed on standard L. botrana diet for $30 \mathrm{~h}$ and then, sprayed with a spore suspension of $1 \times 10^{8}$ conidia B. bassiana $/ \mathrm{ml}$.

4. P. fumosoroseus: Larvae fed on standard L. botrana diet for $30 \mathrm{~h}$ and then, sprayed with a spore suspension of $1 \times 10^{8}$ conidia P. fumosoroseus $/ \mathrm{ml}$.

5. Bt + B. bassiana: Larvae fed on $B t$ diet for $30 \mathrm{~h}$ and then, sprayed with a spore suspension of $1 \times 10^{8}$ conidia B. bassiana $/ \mathrm{ml}$.

6. Bt + P. fumosoroseus: Larvae fed on Bt diet for $30 \mathrm{~h}$ and then, sprayed with a spore suspension of $1 \times 10^{8}$ conidia P. fumosoroseus $/ \mathrm{ml}$.

Post treatment, larvae were provided with a standard L. botrana diet inside Petri dishes (10 larvae per dish). Four cubes of about one cubic centimetre each were added on each plate. Then, plates were sealed and placed into incubators at $25{ }^{\circ} \mathrm{C}, 60 \pm 1 \% \mathrm{RH}$ and 14:10 (L:D) photoperiod (Sanyo - MLR-351H). Each 
treatment consisted of 50 replicates $(5$ dishes $\times 10$ larvae each) and the entire experiment was repeated twice.

Mortality measurements took place 3 and 6 days after the spraying treatments. Any larva which either remained still after contact with the pincers, or was rotten or disintegrated, or presented symptoms of mycosis was recorded as dead. After each mortality measurement, all dead insects were removed from the plates.

\section{Combined effect of $B t$ and $B$. bassiana for the control of $L$. botrana on grapes}

Young $3^{\text {rd }}$ instar L. botrana larvae were exposed to grapes that were previously sprayed by either $B$. bassiana strain GHA (BotaniGard ${ }^{\circledR}$ ES), or Bt var. kurstaki (Dipel-ES) or a combination of both entomopathogens. Control insects were exposed to grapes, sprayed with sterile distilled water. The B. bassiana suspension was adjusted to $1 \times 10^{8}$ conidia/ $\mathrm{ml}$ of sterile distilled water and $0.5 \mathrm{l}$ of such suspension was made. The $B t$ treatment was made by dissolving $2 \mathrm{ml}$ of Dipel ES into $500 \mathrm{ml}$ of sterile distilled water, resulting in a final concentration of 70,400 IU/ml. Equal parts of both liquids $(250 \mathrm{ml})$ were mixed to prepare the combination treatment.

Ripe grapes of Vitis vinifera cv. Sauvignon Blanc were used in the bioassay (11.8-14.1 Baumé degrees at $20^{\circ} \mathrm{C}$ ). Small grape clusters or parts of clusters (6-15 berries each) were totally covered by the spraying liquid. Then, grapes were rested to dry for $2 \mathrm{~h}$. Subsequently, grape clusters were placed into plastic jars $(9.5 \mathrm{~cm} \varnothing$ and $14 \mathrm{~cm}$ height). The lids of the jars were pierced multiple times so air was allowed in the jars. A piece of wet filter paper was placed to cover the bottom of each jar. Grapes of the respective treatment (one small cluster) as well as $10 \mathrm{~L}$. botrana larvae were placed into each jar. All jars were incubated at $25^{\circ} \mathrm{C}, 60 \pm 1 \% \mathrm{RH}$ and $12: 12 \mathrm{~h}$ (L:D) photoperiod for $48 \mathrm{~h}$ and larvae were observed to feed on the grapes. Then, insects from each jar were transferred into a sterile Petri dish, using entomological pincers. Standard L. botrana artificial diet was added into the dishes and insects were incubated under the same conditions as above for 5 more days. Twenty replicates of 10 insects were made for each treatment and the experiment was repeated twice. Mortality measurements were conducted 3, 5 and 7 days after the initial placement of the insects into the jars. Any larva that was rotten, covered by mycelium, or remained still was counted as dead. Dead larvae were removed from the plates during each measurement.

\section{Statistical analysis}

One-way analysis of variance (ANOVA) was conducted to compare different treatments in terms of larval mortality (SPSS, 2008). In both bioassays, Levene's test was used to estimate if variances were assumed homogenous or not. According to those estimations, respective PostHoc tests were used to indicate significant differences between particular treatments (Hilton and Armstrong 2006). In the latter bioassay, Probit analysis was used to estimate the median lethal time $\left(\mathrm{LT}_{50}\right)$ (Reddy et al. 2016). The synergism factor (SF) was calculated by dividing the predicted theoretical mortality value for each treatment by the observed value. According to Tabashnik (1992), an SF ratio equal to 1 was additive, lower than 1 was antagonistic, and a ratio over 1 was synergistic.

\section{Results}

\section{Mortality of $L$. botrana larvae after exposure to $B t$ diet} and subsequent fungal treatment

One-way analysis of variance (ANOVA) showed that even 3 days after the fungal treatments, different applications resulted in significant differences in terms of larval mortality of $L$. botrana $(P=0.0018, F=23.25, d f=5,24)$ (Fig. 1A). Significant differences - among treatments - in mortality of $L$. botrana larvae were also detected in the final measurement that took place 6 days after the fungal treatment $(P<0.001, F=95.12, d f=5,24)$ (Fig. 1B). In both cases, Levene's statistic indicated that variances were not homogenous and therefore Games Howell Posthoc test was used to determine significant differences among treatments. Control insects presented no mortality in the first measurement (3 days post-treatment), while minimum levels of mortality (2\%) were observed 6 days post-treatment (Fig. 1). The highest mortality levels of $L$. botrana larvae were observed when insects were treated with the combination of $B t$ diet and subsequent treatment with B. bassiana (91\%) and P. fumosoroseus (95\%). Those results indicated that combination treatments differed significantly from single treatments causing remarkably high mortality levels. The combination of $B t$ diet and subsequent $B$. bassiana treatment showed a synergistic action, while additive effects were observed in the case of $B t+P$. fumosoroseus. About $35 \%$ of insects sprayed with fungal suspensions presented symptoms of external mycosis 11 days post-treatment.

\section{Combined effect of $B t$ and $B$. bassiana for the control on $L$. botrana on grapes}

There were statistically significant differences among treatments 7 days post placement of the insects into the jars that contained treated grapes $(P<0.001, F=84.62$, $d f=3,76$ ). Single $B t$ and $B$. bassiana treatments resulted in equal larval mortality (37\%). Mortality in the combination treatment was significantly higher than single treatments, while all treatments differed significantly from control (Fig. 2). Tukey HSD test was used to determine differences between treatments due to Levene's test which proved homogeneity within variances $(P=0.201)$. 


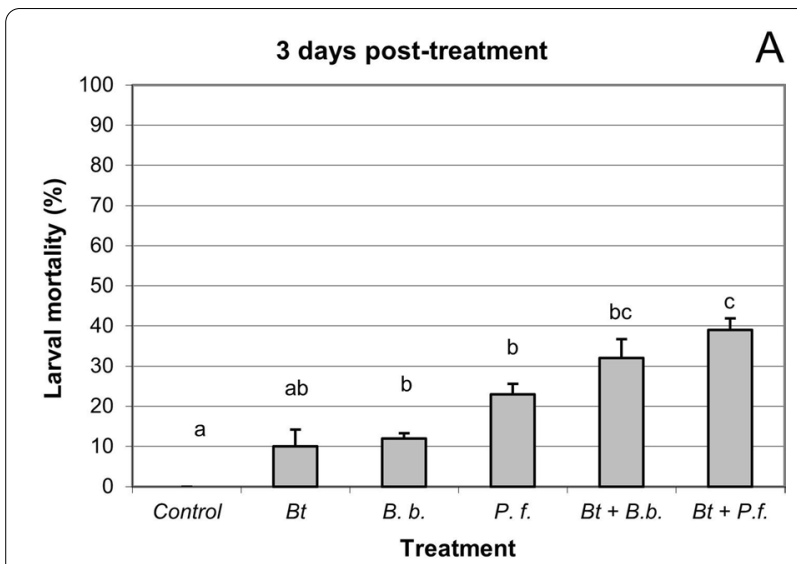

6 days post-treatment

B

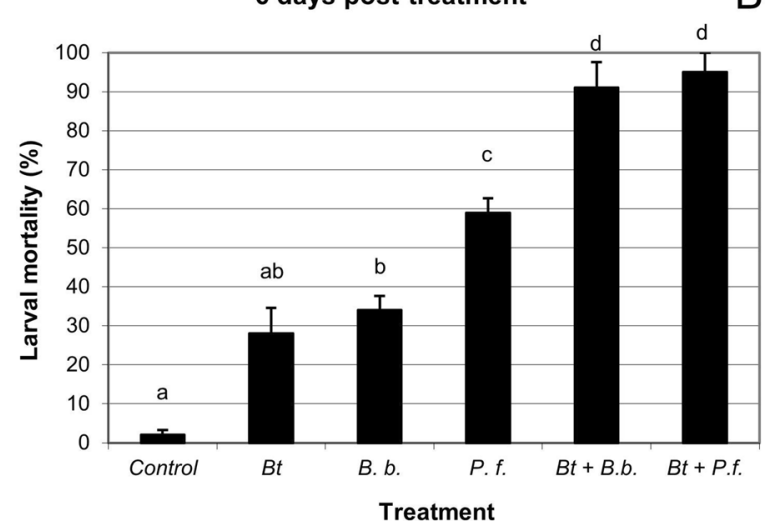

Fig. 1 Percentages of mean mortality of Lobesia botrana larvae, 3 (A) and 6 (B) days after the fungal treatments (Bacillus thuringiensis diet exposure began $30 \mathrm{~h}$. prior to fungal treatments). Different letters indicate statistically significant differences between treatments. $B t=$ Bacillus thuringiensis, B. b. $=$ Beauveria bassiana, P. f. $=$ Paecilomyces fumosoroseus

Measurements taken 3 and 5 days post-treatment presented low levels of mortality in all treatments and therefore, results were neither taken into consideration nor statistically analysed. According to Probit analysis, the $\mathrm{LT}_{50}$ (median lethal time 50\%) for the single $B t$ treatment was 8.43 , for the single $B$. bassiana treatment was 7.87 and for the combination $B t+B$. bassiana treatment was 6.3 (days), at standard concentrations of $1 \times 10^{8}$ conidia/ $\mathrm{ml}(B$. bassiana) and 70,400 IU/ml $(B t)$. Additive effects were observed (when combining $B t$ and B. bassiana), but in this case, no synergy was suggested.

\section{Discussion}

Results published in previous assays indicated efficacy of $B t$ on the control of L. botrana. Lethal effects were observed under field and laboratory conditions by Roditakis (1986), while Ifoulis and Savopoulou-Soultani (2004) tested various $B t$ formulations at laboratory

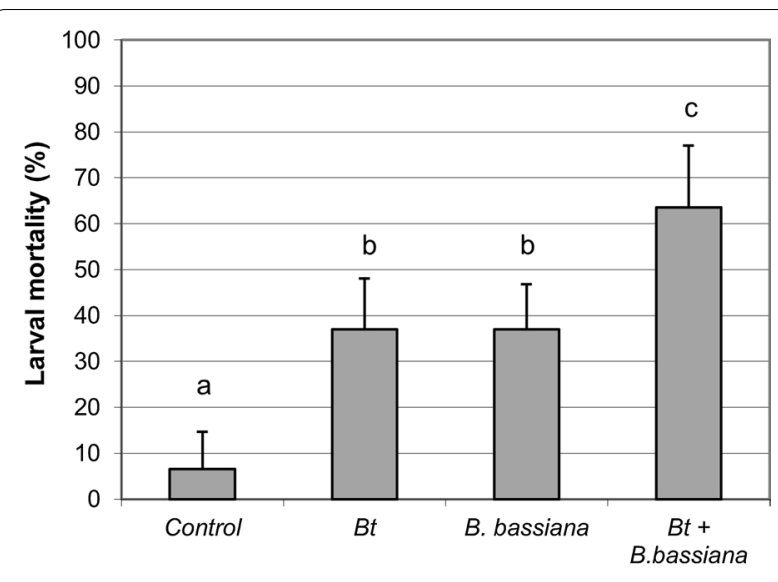

Treatment

Fig. 2 Percentages of mean mortality of Lobesia botrana larvae, seven days after their placement into jars that contained treated grapes. Different letters indicate significant differences between treatments. $B t=$ Bacillus thuringiensis, $B$. . $b .=$ Beauveria bassiana, $P$. $f$. = Paecilomyces fumosoroseus

bioassays. Ruiz de Escudero et al. (2007) also reported the efficiency of $B t$ toxins on the control of L. botrana. Analogous Research was extended to several more lepidopteran Pests (Ruiz de Escudero et al. 2014). Furthermore, selective action ( $B t$ controls $L$. botrana without harming its predators and parasitoids) has been indicated (Tzanakakis and Katsoyiannos 2003). However, in a recent study, $B t$ showed to affect host-searching behaviour and reproductive activity of the parasitoid Palmistichus elaeisis reducing its immature production and survival (Rolim et al. 2020). Those results indicate low compatibility between bio-insecticides based on Bacillus $s p$. and a group of wasp parasitoids. In another study, mortality levels of $L$. botrana after being treated by 5 commercial formulations of Bt, (B. thuringiensis subsp. kurstaki/subsp. aizawai), Dipel (Bt subsp. kurstaki), Bactospeine (Bt subsp. kurstaki), Xentari (Bt subsp. aizawai) and BMP (Bt encapsulated $\delta$-entotoxin), were recorded by Anagnou and Kontodimas (2003) under laboratory conditions. All products (which were added on artificial diet) caused high larval mortality. Results derived from both bioassays of the present study indicated that $B t$ did not inhibit the action of EPF against $L$. botrana. In contrast, combination treatments resulted in higher mortality levels of L. botrana than the single treatments presenting additive action or even synergism.

Synergistic action between $B t$ and EPF has been previously reported by Costa et al. (2001) who investigated mortality of the Colorado potato beetle (Leptinotarsa decemlineata) after sub-lethal stress caused by $B t$ and subsequent exposure to B. bassiana. Synergy was indicated particularly when insects were exposed to the 
highest concentration of $B$. bassiana. In other studies, Wraight and Ramos (2005) found that combined treatments produced a statistically significant (6-35\%) greater reduction in larval populations than would have been predicted to have with $B t$ and $B$. bassiana when applied separately against the Colorado potato beetle. Moreover, high mortality levels (near 70\%) were caused by the combination of $B t$ with $B$. bassiana to Ostrinia nubilalis larvae (Lewis et al. 1996). Also, Ma et al. (2008) presented results that indicated the additive effect of $B t$ and B. bassiana on mortality of Ostrinia furnacalis in most cases, except for the combination of Cry1Ac $(0.2 \mu \mathrm{g} / \mathrm{g})$ and $B$. bassiana $\left(1.8 \times 10^{6}\right.$ conidia/ml $)$ that showed antagonism. EPF have also presented enhanced efficacy when applied in combination treatments not only with other entomopathogens but also with synthetic insecticides (Furlong and Groden 2001). Regarding their co-existence with plant extracts, EPF have shown both inhibited action (Mann and Davis 2020) and positive interaction as Neem seed cake improved pathogenicity of the fungus Metarhizium anisopliae against the Black Vine Weevil (Shah et al. 2008).

\section{Conclusions}

Both $B t$ and EPF have showed remarkable potential as bio-control agents of many lepidopteran and coleopteran pests. Research is needed to investigate the biotic and abiotic factors that affect interactions between different entomopathogens in the control of a specific target pest. The additive and synergistic action between $B t$ and EPF - concluded from the present assay - indicated that both entomopathogens can be applied in combination treatments for the control of $L$. botrana and can be included simultaneously in Integrated Pest Management (IPM) programs designed for vineyards.

\section{Abbreviations \\ Bt: Bacillus thuringiensis; EPF: Entomopathogenic fungi; $\mathrm{LT}_{50}$ : Median lethal time; IU: International units; SDA: Sabouraud Dextrose Agar; RH: Relative humidity; IPM: Integrated Pest Management; SF: Synergism factor.}

\section{Acknowledgements \\ Sincere gratitude to Professor Simon Gowen as well as Barbara Pembroke from the Dept. of Agriculture (University of Reading, UK) for being an endless source of inspiration. Greeting to the Greek State's Scholarship Foundation (I.K.Y.) for the financial support they provided during first author's PhD stud- ies. Many thanks to Benaki Phytopathological Institute (Athens - Greece) for providing assistance and support.}

\section{Authors' contributions}

EB conducted the bioassays, while EB and EK designed the experiments, carried out the statistical analysis of data and wrote the manuscript. All authors read and approved the final manuscript.

\section{Funding}

Not applicable.

\section{Availability of data and materials}

The datasets used and analysed during the current study are available from the corresponding author on reasonable request.

\section{Declarations}

Ethics approval and consent to participate

Not applicable.

\section{Consent for publication}

Not applicable.

\section{Competing interests}

The authors declare that they have no competing interests.

Received: 2 April 2021 Accepted: 31 July 2021

Published online: 09 August 2021

\section{References}

Anagnou M, Kontodimas DC (2003) Laboratory tests of the effect of Bacillus thuringiensis on grape berry moth Lobesia botrana (Lepidoptera: Tortricidae) and on the pseudococcids' predator Nephus includens (Coleoptera: Coccinellidae). Bull OILB-SROP 26:117-119

Benelli G, Pavoni L, Zeni V, Ricciardi R, Cosci F, Cacopardo G, Gendusa S, Spinozzi E, Petrelli R, Cappellacci L, Maggi F, Pavela R, Bonacucina G, Lucchi A (2020) Developing a highly stable Carlina acaulis essential oil nanoemulsion for managing Lobesia botrana. Nanomaterials 10(9):1867

Costa SD, Barbercheck ME, Kennedy GG (2001) Mortality of Colorado Potato Beetle (Leptinotarsa decemlineata) after sublethal stress with the CryllIA I-Endotoxin of Bacillus thuringiensis and subsequent exposure to Beauveria bassiana. J Invertebr Pathol 77:173-179

Delbac L, Thiery D (2015) Damage to grape flowers and berries by Lobesia botrana larvae (Denis \& Schiffernüller) (Lepidoptera: Tortricidae), and relation to larval age. Aust J Grape Wine Res 22(2):256-261

Delbac L, Lecharpentier P, Thiery D (2010) Larval instars determination for the European Grapevine Moth (Lepidoptera: Tortricidae) based on the frequency distribution of head-capsule widths. Crop Prot 29:623-630

Durmuşoğlu E, Hatipoğlu A, Gurkan MO, Moores G (2015) Comparison of different bioassay methods for determining insecticide resistance in European Grapevine Moth, Lobesia botrana (Denis \& Schiffermüller) (Lepidoptera: Tortricidae). Turk J Entomol 39(3):271-276

Furlong MJ, Groden E (2001) Evaluation of synergistic interactions between the Colorado Potato Beetle (Coleoptera: Chrysomelidae) pathogen Beauveria bassiana and the insecticides, Imidacloprid, and Cyromazine. J Econ Entomol 94:344-356

Galindo-Velasco E, Lezama-Gutiérrez R, Cruz-Vázquez C, Pescador-Rubio A, Angel Sahagún CA, Ojeda M, Rodriguez-Vivas Rl, Contreras-Lara D (2015) Efficacy of entomopathogenic fungi (Ascomycetes: Hypocreales) against adult Haematobia irritans (Diptera: Muscidae) under stable conditions in the Mexican dry tropics. Vet Parasitol 209:173-178

Guo W, Kain W, Wang P (2019) Effects of disruption of the peritrophic membrane on larval susceptibility to Bt toxin Cry1Ac in cabbage loopers. J Insect Physiol 117:103897

Gutierrez AP, Ponti L, Gilioli G, Baumgärtner J (2018) Climate warming effects on grape and grapevine moth (Lobesia botrana) in the Palearctic region: climate warming effect on grape and grapevine moth. Agric for Entomol 20:255-271

Hilton A, Armstrong RA (2006) Statnote 6: post-hoc ANOVA tests. Microbiologist 5:34-36

Ifoulis AA, Savopoulou-Soultani M (2004) Biological control of Lobesia botrana (Lepidoptera: Tortricidae) larvae by using different formulations of Bacillus thuringiensis in 11 vine cultivars under field conditions. J Econ Entomol 97:340-343

Ioriatti C, Anfora G, Tasin M, De Cristofaro A, Witzgall P, Lucchi A (2011) Chemical ecology and management of Lobesia botrana (Lepidoptera: Tortricidae). J Econ Entomol 104:1125-1137

Lewis LC, Berry EC, Obrycki JJ, Bing LA (1996) Aptness of insecticides (Bacillus thuringiensis and carbofuran) with endophytic Beauveria bassiana, in 
suppressing larval populations of the European corn borer. Agric Ecosyst Environ 57:27-34

López-Plantey R, Papura D, Couture C, Thiery D, Pizzuolo P, Bertoldi M, Lucero $\mathrm{G}$ (2019) Characterization of entomopathogenic fungi from vineyards in Argentina with potential as biological control agents against the European grapevine moth Lobesia botrana. Biol Control 64:501-511

Ma XM, Liu XX, Ning X, Zhang B, Han F, Guan XM, Tan YF, Zhang QW (2008) Effects of Bacillus thuringiensis toxin Cry $1 \mathrm{Ac}$ and Beauveria bassiana on Asiatic corn borer (Lepidoptera: Crambidae). J Invertebr Pathol 99:123-128

Mann AJ, Davis TS (2020) Plant secondary metabolites and low temperature are the major limiting factors for Beauveria bassiana (Bals.-Criv.) Vuill (Ascomycota: Hypocreales) growth and virulence in a bark beetle system. Biol Control 141:104130

Mansour MY, Al-Attar J (2014) Effects of gamma irradiation on the grape vine moth Lobesia Botrana, Mature Larvae. Radiat Phys Chem 97:370-373

Moreau J, Villemant C, Benrey B, Thiary D (2010) Species diversity of larval parasitoids of the European grapevine moth (Lobesia botrana, Lepidoptera: Tortricidae): the influence of region and cultivar. Biol Control 54:300-306

Moustafa MAM, Saleh MA, Ateya IR, Kandil MA (2018) Influence of some environmental conditions on stability and activity of Bacillus thuringiensis formulations against the cotton leaf worm, Spodoptera littoralis (Boisd.) (Lepidoptera: Noctuidae). Egypt J Biol Pest Control 28:61

Reddy G, Antwi F, Shrestha G, Kuriwada T (2016) Evaluation of toxicity of biorational insecticides against larvae of the alfalfa weevil. Toxicol Rep 3:473-480. https://doi.org/10.1016/j.toxrep.2016.05.003

Reineke A, Selim M (2019) Elevated atmospheric CO2 concentrations alter grapevine (Vitis vinifera) systemic transcriptional response to European grapevine moth (Lobesia botrana) herbivory. Sci Rep 9:2995

Roditakis NE (1986) Effectiveness of Bacillus thuringiensis Berliner var. kurstaki on the grape berry moth Lobesia botrana Den. and Shiff. (Lepidoptera: Tortricidae) under field and laboratory conditions in Crete. Entomol Hellenica 4:31-35

Rolim GDS, Plata-Rueda A, Martínez LC, Ribeiro GT, Serrão JE, Zanuncio JC (2020) Side effects of Bacillus thuringiensis on the parasitoid Palmistichus elaeisis (Hymenoptera: Eulophidae). Ecotoxicol Environ Saf 189:109978
Ruiz de Escudero I, Estela A, Escriche B, Caballero P (2007) Potential of the Bacillus thuringiensis toxin reservoir for the control of Lobesia botrana (Lepidoptera: Tortricidae), a major pest of grape plants. Appl Environ Microbiol 73:337-340

Ruiz de Escudero I, Banyuls N, Bel Y, Maeztu M, Escriche B, Mupoz D, Caballero P, Ferre J (2014) A screening of five Bacillus thuringiensis Vip3A proteins for their activity against lepidopteran pests. J Invertebr Pathol 117:51-55

Schünemann R, Knaak N, Fiuza LM (2014) Mode of action and specificity of Bacillus thuringiensis Toxins in the control of caterpillars and stink bugs in soybean culture. ISRN Microbiol 2014:135675

Shah FA, Gaffney M, Ansari MA, Prasad M, Butt TM (2008) Neem seed cake enhances the efficacy of the insect pathogenic fungus Metarhizium anisopliae for the control of black vine weevil, Otiorhynuchs sulcatus (Coleoptera: Curculionidae). Biol Control 44:111-115

SPSS Inc. (2008) Released 2008. SPSS statistics for windows, version 17.0. SPSS Inc., Chicago

Tabashnik BE (1992) Evaluation of synergism among Bacillus thuringiensis toxins. Appl Environ Microbiol 58:3343-3346

Tzanakakis ME, Katsoyiannos BI (2003) Insect pests of fruit trees and vines. Agrotypos AE, Athens, pp 38-44

Vogelweith F, Thiery D, Moret Y, Colin E, Motreuil S, Moreau J (2014) Defense strategies used by two sympatric vineyard moth pests. J Insect Physiol 64:54-61

Wraight SP, Ramos ME (2005) Synergistic interaction between Beauveria bassiana- and Bacillus thuringiensis tenebrionis-based biopesticides applied against field populations of Colorado potato beetle larvae. J Invertebr Pathol 90:139-150

Zimmermann G (1986) The Galleria bait method for detection of entomopathogenic fungi in soil. J Appl Entomol 102:213-215

\section{Publisher's Note}

Springer Nature remains neutral with regard to jurisdictional claims in published maps and institutional affiliations.

\section{Submit your manuscript to a SpringerOpen ${ }^{\odot}$ journal and benefit from:}

- Convenient online submission

- Rigorous peer review

- Open access: articles freely available online

- High visibility within the field

Retaining the copyright to your article

Submit your next manuscript at $\boldsymbol{\nabla}$ springeropen.com 